\title{
Sleep and Fire: Who is at Risk and Can the Risk be Reduced?
}

\author{
DOROTHY BRUCK and MICHELLE BALL \\ School of Psychology and Centre for Environmental Safety and Risk Engineering \\ Victoria University \\ Melbourne, Australia
}

\begin{abstract}
While sleep is clearly a major risk factor for dying in a fire, in this review it is argued that in most fire fatalities during the sleeping period additional risk factors are also operating. This view is consistent with the data from empirical sleep studies and smoke alarms where most (but not all) adults tested will awaken to a signal reaching the pillow at $75 \mathrm{dBA}$. However, research suggests that significant 'staying asleep' risk factors include high levels of background noise, being a heavy sleeper, sleep deprivation, being a child, sleeping tablets, alcohol intoxication, hearing impairment and being over age 60 (for high frequency signals). Recent sleep studies that have compared the waking effectiveness of different alarm signals (using children, sober adults and alcohol intoxicated adults) suggest that the high frequency beeping signal (usually around $3000 \mathrm{~Hz}$ ) currently used in smoke alarms is significantly less effective in waking 'at risk' groups than either a voice alarm (300-2500 Hz) or a low pitched beeping signal (500-2500 Hz). Compared to the high pitched signal, the latter two signals required a $13 \mathrm{dBA}$ lower volume to awaken sober adults and, when presented at $89 \mathrm{dBA}$ to 6-10 year olds, were almost twice as likely to cause awakenings. The findings suggest that alarm signals of a frequency below $2500 \mathrm{~Hz}$ will reduce the likelihood of individuals sleeping through a smoke alarm and further research should seek to more narrowly define the most effective frequency band and signal for arousal from sleep.
\end{abstract}

KEYWORDS: alarms, smoke detectors, sleep, response patterns, human behavior, alcohol

\section{INTRODUCTION}

In this review the issue of sleep and fire will be addressed from two different angles. The first section will discuss who dies in fires under what circumstances and consider the extent to which sleep is a risk factor for dying in a fire. The second section will review different empirical studies that have investigated whether people will awaken to different fire cues and different smoke alarm signals and under what circumstances. The implications of these two research approaches for effective emergency alarms will then be discussed.

\section{SLEEP AND FIRE STATISTICS}

An analysis of apartment fires in the US that were attended by the fire brigade during the main sleeping period (1am - 4am) from 1983 to 1994 shows that for 98.5\% of fires, residents were able to respond in sufficient time to avoid death [1]. Only $1.5 \%$ of the fires during this three hour sleeping period resulted in fatalities. In some of these fire scenarios 
the victim may have been awake but died through their intimate involvement with the fire and/or inability to escape in time. Some people would have been awoken (by fire cues, alarms or another occupant) too late and been overcome by smoke or flames prior to escape or in attempting rescue or extinguishment. In other cases they were asleep and stayed asleep. That is, they did not awaken to the fire cues (sound, smell, visual), other disturbances, or to a smoke alarm that may have sounded. Estimates suggest that $20.3 \%$ of US home fire deaths occurred in homes where the smoke alarms were present and operated [2] (1989-1998) and this translates to about 770 victims annually [3].

There have been several studies categorising the characteristics of people who have died in fires, noting whether they have been asleep, bedridden, sick etc. Figure 1 shows a statistical analysis of the NFIRS database (1983-1994) that contains 420,315 fires attended by fire brigades in apartment buildings in the US that resulted in 3111 fatalities [4]. It reflects what is shown in numerous studies, that being asleep is clearly a risk factor for dying in a fire. The graph shows that sleeping is a risk factor no matter which area is the room of fire origin. Unfortunately, what is not known from this data is any more detail about those who died in their sleep from a fire. For example, to what extent were they unimpaired, sober, able-bodied people who slept through fire cues and/or signals?

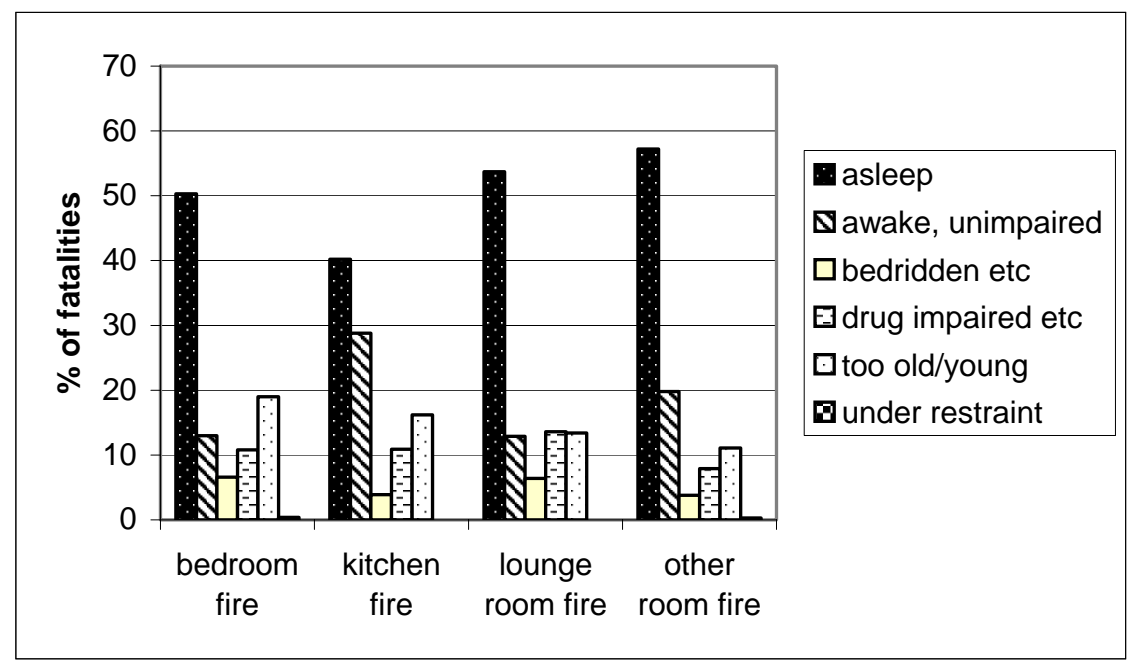

Fig. 1. Percentage of fatalities according to fire origin in different rooms, by condition before death [4].

A breakdown of the fire fatality characteristics of over 3000 victims of residential fires in Japan [5] shows that across all the fatalities, 46.5\% were asleep. Among the 6-64 yr olds $65 \%$ had ingested alcohol at the time of their death and of these, $40 \%$ were asleep. Secondary analyses of this data [6], based on some assumptions, concluded that among those that were asleep perhaps only about a quarter were asleep, able bodied and unimpaired (see Fig. 2). 


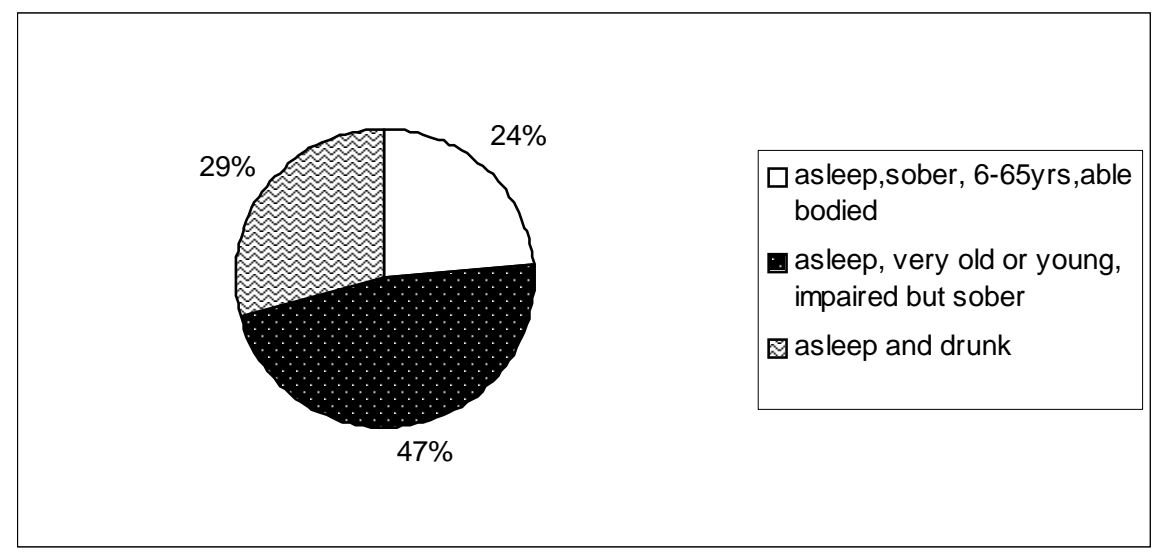

Fig. 2. Fire fatalities when asleep: impaired and unimpaired ([6], based on [5]).

It is not known how many victims in the $24 \%$ "able bodied" category (shown in Fig. 2) were school aged children but as they are known to be heavy sleepers (see below) they may be disproportionately represented within the group. Using US incident reports where smoke alarms were said to have operated, the circumstances around the death of 22 children aged 6 to 15 years who were apparently asleep at the time of the fire were examined [3]. The data suggest that 5 of these 22 children clearly slept through a smoke alarm, 1 awoke to smoke and 4 were awoken by a parent. For 12 of the child victims it was unknown whether they were awoken or not, and if so, what awoke them, but they did not succeed in escaping in time. Although the numbers are small, it would seem that in most of the fatalities the children continued to sleep after other members of the household were alerted to the fire.

An analysis of coronial reports of fire victims in Australia [7] breaks down information on whether the victim was awake or asleep by age (see Fig. 3). Across all the fatalities $(n=150)$, two thirds of the victims were asleep. Between ages 5-64 years victims were much more likely to be asleep than awake at the time of the fire. This difference was less for the very young and very old victims. Not surprisingly the vast majority (86\%) of victims of night fires (8pm to 8am) were asleep. However, 31\% of day fire fatalities were also asleep. Clearly being asleep is a more accurate indicator of risk than time of day. Alcohol often played a role, especially in young and middle aged male victims. Overall, nearly half of all the 18-74 year old victims had blood alcohol readings over 0.05 (and this is likely to be an underestimate as only $70 \%$ in this age group were tested). 


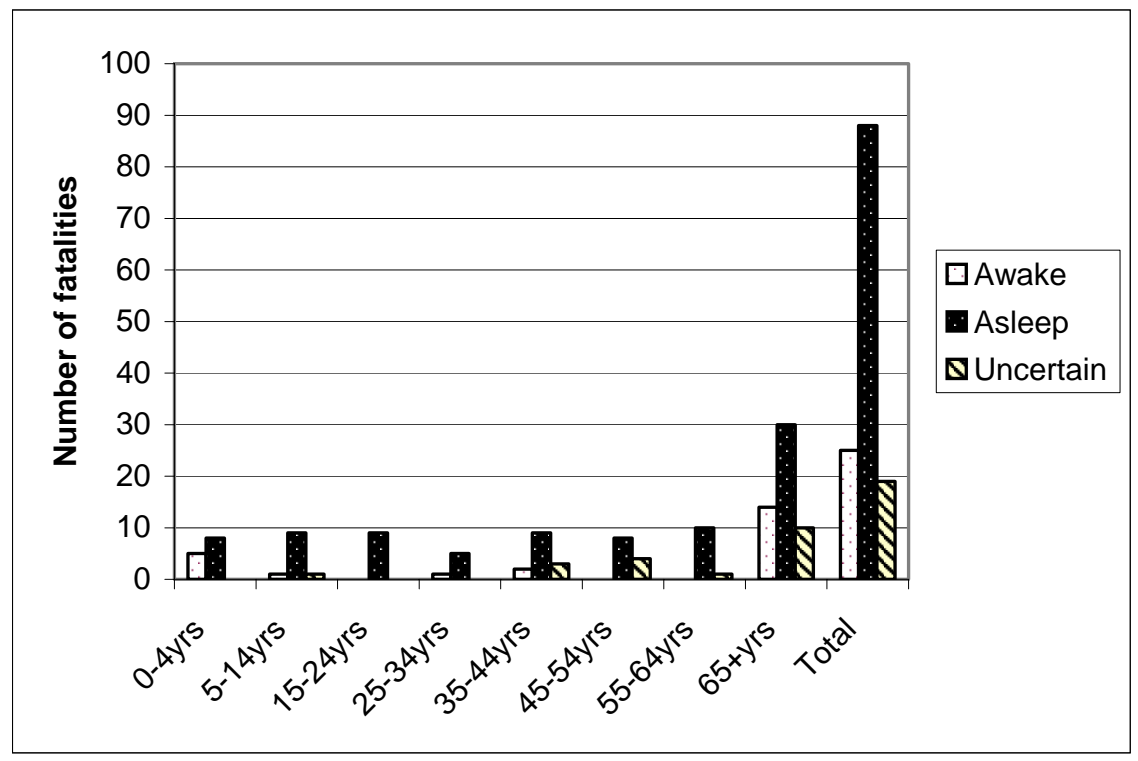

Fig. 3. Age of victim according to whether awake or asleep at time of fire [7].

Death from fire starting while asleep results from not responding, responding inappropriately, delayed response or an inability to escape. However, we know that in $98.5 \%$ of fires occurring during the main sleeping period no one will die, so most people will wake and be able to escape. Where people have died from a fire starting when they were asleep, it seems likely some additional risk factors may be operating (apart from being asleep), which increase the chance of becoming a fire fatality. Alcohol is known to be soporific, and from the discussions above and other studies [8], alcohol consumption is clearly a risk factor for fire fatality. Some school aged fire victims are documented to have slept through all cues, but the numbers are small. In order to identify the "staying asleep risk factors" we cannot rely on fatality data from real fires because too often it is uncertain what key risk factors were operating. In particular, it is often unclear to what extent multiple risk factors existed (e.g., asleep and drug impaired rather than just one risk factor). In the absence of more comprehensive real fire data an alternative approach is to consider what the empirical sleep studies tell us about which factors reduce the chance of waking up in a fire scenario. Knowing this may lead to improvements in alerting systems.

Prior to discussing the sleep studies it is useful to provide some context information about smoke detector signals and sound intensity levels. Most residential smoke detectors currently sold emit beeps of a single high frequency which may be between $3000 \mathrm{~Hz}$ and $5000 \mathrm{~Hz}[9,10,11]$ with a sound intensity in the vicinity of $85 \mathrm{dBA}$ at $10 \mathrm{ft}$. Earlier smoke alarms sometimes combined two modulating signals peaking at $2000 \mathrm{~Hz}$ and $4000 \mathrm{~Hz}$. [12]. A smoke alarm located in the hallway will penetrate a closed bedroom door with a resulting bedside volume of 51-68 dBA, depending on the room configuration and materials [13]. A smoke alarm signal level of either 70 dBA (e.g., US) or 75 dBA (e.g., UK, Canada \& Australia) at the bed head in sleeping areas is recommended or required in the regulations of many countries. In the US most smoke detectors now emit the 
Temporal 3 (T-3) pattern. The T-3 is a temporal pattern of a signal being on and off for 0.5 seconds three times in succession followed by a 1.5 second pause. The T- 3 signal is set out in ISO 8201 [14] and is now required as the emergency fire evacuation signal by many regulatory authorities. The ISO does not specify the frequency of the T-3, apparently so that the signal can be matched to any background noise to optimize its perception [15].

\section{EMPIRICAL SLEEP STUDIES}

There is a considerable literature on sleep and arousal in different circumstances and studies in this area have been extensively reviewed previously $[6,16]$. This paper will mainly focus on those studies that have used fire cues or alarm signals to investigate awakening. These will be considered in three sections: adults (unimpaired), children, adults (impaired).

\section{Adults}

Table 1 (see following page) summarises the six empirical studies that have investigated the ability of adult participants to awaken to smoke alarm signals. Inspection of the results in the various studies suggests that most adults would awaken to a $75 \mathrm{dBA}$ high frequency signal. However, it is not unusual to find heavy sleepers. The typical percentage that will not awaken is unknown but in one study [10] using self reported 'deep' sleepers, 2 of the 12 young adults (sober) did not awaken to the high pitched alarm at $85 \mathrm{dBA}$ and one of these did not awaken to three minutes of a $95 \mathrm{dBA}$ alarm. All of the studies used a high pitched beeping alarm of at least $2000 \mathrm{~Hz}$, except [10], where responsiveness to the high pitch alarm was contrasted to a female voice and a low pitched T-3 alarm. In this study a modified method of limits procedure was used (see footnote to Table 1), which allowed determination of the average sound threshold that would awaken participants. Both low frequency signals (voice and T-3) resulted in an average threshold of $59 \mathrm{dBA}$, while the high pitched beeps needed a sound intensity $13 \mathrm{dBA}$ higher to arouse the sleepers.

The participants used in the studies summarised in Table 1 are sleeping in what we may consider "ideal" circumstances. That is, they are not under the influence of alcohol or drugs, have normal hearing and are normally not sleep deprived. The exception to this is the study by Bruck and Horasan [17] in which it was found post hoc that those participants who had slept through one or both of the $60 \mathrm{dBA}$ alarm signals were sleep deprived, having stayed up most of the night before participating in the experiment in order to study for exams. Thus they may be considered as "impaired", although the sleep loss variable was not systematically manipulated. Earlier studies have also shown that sleep deprivation reduces a person's ability to respond to signals while asleep $[18,19]$. This factor may be important in an alarms context as recent research suggests that chronic sleep loss is widespread, both in day workers and shift workers [20,21]. 
Table 1. Summary of details from articles on arousal to smoke alarms in adults.

\begin{tabular}{|c|c|c|c|c|c|c|c|c|}
\hline $\begin{array}{l}\text { Authors } \\
\text { and Year }\end{array}$ & $\begin{array}{l}\text { Signal } \\
\text { details }\end{array}$ & $\begin{array}{l}\text { dBA } \\
\text { at } \\
\text { pillow }\end{array}$ & $\begin{array}{l}\text { Back- } \\
\text { groun } \\
\text { d } \\
\text { dBA }\end{array}$ & $\begin{array}{l}\text { Time of } \\
\text { night/ } \\
\text { sleep } \\
\text { stage }\end{array}$ & $\mathbf{N}$ & $\begin{array}{l}\text { Age: } \\
\text { years }\end{array}$ & $\begin{array}{l}\text { Result: } \\
\% \\
\text { awoke }\end{array}$ & $\begin{array}{l}\text { Result: } \\
\text { latencies } \\
\text { of those } \\
\text { who } \\
\text { awoke }\end{array}$ \\
\hline \multirow{5}{*}{$\begin{array}{l}\text { Nober et } \\
\text { al } 1981 \\
{[22]}\end{array}$} & \multirow[t]{5}{*}{$\begin{array}{l}3000- \\
5000 \mathrm{~Hz}\end{array}$} & 55 & $\mathrm{n} / \mathrm{a}$ & \multirow[t]{5}{*}{ Vary-ing } & 10 & \multirow[t]{5}{*}{$18-29$} & $100 \%$ & $\begin{array}{l}\text { within } 21 \\
\text { sec }\end{array}$ \\
\hline & & 70 & $\mathrm{n} / \mathrm{a}$ & & 10 & & $100 \%$ & $\begin{array}{l}\text { within } 16 \\
\text { sec }\end{array}$ \\
\hline & & 85 & $\mathrm{n} / \mathrm{a}$ & & 10 & & $100 \%$ & $\begin{array}{l}\text { within } 11 \\
\text { sec }\end{array}$ \\
\hline & & 70 & 53 & & 10 & & $100 \%$ & $\begin{array}{l}\text { within } 85 \\
\text { sec }\end{array}$ \\
\hline & & 55 & 53 & & 10 & & $100 \%$ & $\begin{array}{l}\text { within } 75 \\
\text { sec }\end{array}$ \\
\hline \multirow{3}{*}{$\begin{array}{l}\text { Kahn } \\
1984 \text { [12] }\end{array}$} & \multirow{3}{*}{$\begin{array}{l}2000- \\
4000 \\
\mathrm{~Hz}\end{array}$} & 44 & \multirow[t]{3}{*}{44} & \multirow{3}{*}{$\begin{array}{l}2,4 \text { and } \\
6 \text { hrs } \\
\text { after } \\
\text { lights out }\end{array}$} & 12 & \multirow{3}{*}{$\begin{array}{l}\text { mean } \\
=21.3\end{array}$} & $25 \%$ & \multirow{3}{*}{$\begin{array}{l}\text { within } 20 \\
\text { minutes }\end{array}$} \\
\hline & & 54 & & & 12 & & $50 \%$ & \\
\hline & & 78 & & & 12 & & $100 \%$ & \\
\hline \multirow{3}{*}{$\begin{array}{l}\text { Bruck } \\
\text { and } \\
\text { Horasan } \\
1995 \text { [17] }\end{array}$} & \multirow{3}{*}{$\begin{array}{l}2000- \\
4000 \\
\mathrm{~Hz}\end{array}$} & \multirow[t]{3}{*}{60} & \multirow[t]{3}{*}{$<30$} & stage 4 & 8 & \multirow[t]{3}{*}{$18-24$} & $87 \%^{a}$ & $\begin{array}{l}\text { Mean = } \\
79 \mathrm{sec}\end{array}$ \\
\hline & & & & stage 2 & 8 & & $75 \%^{a}$ & $\begin{array}{l}\text { Mean = } \\
12 \mathrm{sec}\end{array}$ \\
\hline & & & & REM & 8 & & $75 \%{ }^{\mathrm{a}}$ & $\begin{array}{l}\text { Mean = } \\
20 \mathrm{sec}\end{array}$ \\
\hline $\begin{array}{l}\text { Bruck } \\
1999 \text { [23] }\end{array}$ & $\begin{array}{l}2000- \\
4000 \mathrm{~Hz}\end{array}$ & 60 & $\mathrm{n} / \mathrm{a}$ & $\begin{array}{l}1 \mathrm{am}- \\
4.30 \mathrm{am}\end{array}$ & 16 & 30-59 & $\begin{array}{l}100 \% \text { on } \\
\text { both } \\
\text { nights }\end{array}$ & $\begin{array}{l}\text { within } 32 \\
\text { sec }\end{array}$ \\
\hline \multirow[t]{3}{*}{$\begin{array}{l}\text { Ball and } \\
\text { Bruck } \\
2004 \text { [10] }\end{array}$} & $\begin{array}{l}\begin{array}{l}\text { Female } \\
\text { voice } \\
300- \\
2500 \mathrm{~Hz}\end{array} \\
\end{array}$ & \multirow[t]{3}{*}{$\mathrm{b}$} & \multirow[t]{3}{*}{$\mathrm{n} / \mathrm{a}$} & \multirow[t]{3}{*}{ stage 4} & \multirow[t]{3}{*}{12} & \multirow[t]{3}{*}{$18-25$} & $\begin{array}{l}59.6 \\
\text { dBA } \\
(14.06)^{c}\end{array}$ & \\
\hline & $\begin{array}{l}4000- \\
5000 \mathrm{~Hz}\end{array}$ & & & & & & $\begin{array}{l}72.5 \\
\text { dBA } \\
(17.77)^{c}\end{array}$ & \\
\hline & $\begin{array}{l}\text { T-3 } \\
500- \\
2500 \mathrm{~Hz}\end{array}$ & & & & & & $\begin{array}{l}59.2 \\
\text { dBA } \\
(15.64)^{c}\end{array}$ & \\
\hline \multirow{2}{*}{$\begin{array}{l}\text { Ashley et } \\
\text { al } 2005 \\
\text { [11] }\end{array}$} & \multirow{2}{*}{$\begin{array}{l}3100 \\
\mathrm{~Hz}\end{array}$} & \multirow[t]{2}{*}{$>75$} & \multirow[t]{2}{*}{$\mathrm{n} / \mathrm{a}$} & stage 4 & \multirow[t]{2}{*}{32} & \multirow[t]{2}{*}{ adult } & \multirow[t]{2}{*}{$96 \%$} & \multirow{2}{*}{$\begin{array}{l}\text { within } 120 \\
\text { sec }\end{array}$} \\
\hline & & & & $\begin{array}{l}\text { stage } 2 \\
\text { REM }\end{array}$ & & & & \\
\hline
\end{tabular}

${ }^{a}$ To two presentations

${ }^{\mathrm{b}}$ Modified method of limits: Presented signals of increasing volume of $5 \mathrm{dBA}$ every 30 seconds

${ }^{\mathrm{C}}$ Mean (SD) dBA arousal threshold 
The ability of sleeping adults to respond to low level cues that mimic the early presence of fire was tested using auditory, visual and olfactory cues [24]. It was found that there was a relatively high rate of arousal to low level sound cues (received at 38-48 dBA), wherein $91 \%$ awoke to a crackling sound and $83 \%$ to a shuffling sound. Only $49 \%$ responded to a flickering light of less than 5 lux, while $59 \%$ awoke to the smoke odour. It was concluded that most adults who are unimpaired would be aroused from sleep by low level fire cues, particularly as in a real fire multiple cues occur. Among low level fire cues, auditory signals are clearly the most successful.

\section{Children}

Most parents will readily agree that their children can be very difficult to wake up. The reason for this is probably their hypothesised higher electroencephalogram (EEG) energy levels [25] but other factors relating to their immature brain development (e.g., the areas responsible for making judgments) may also play a role. Some indication of how arousal thresholds change with age is given by the data in Table 2, which shows thresholds to a 3 second 1,500 $\mathrm{Hz}$ tone delivered via an earphone insert (maximum administered was $120 \mathrm{~dB}$ ) [26]. Note especially the high threshold values for those aged below 16 and the large standard deviations across all age groups.

Table 2. Auditory arousal thresholds in children and young adults [26].

\begin{tabular}{l|llll} 
& $\mathbf{N}$ & Age (yrs) & $\begin{array}{c}\text { Average } \\
\text { threshold (dB) }\end{array}$ & $\begin{array}{c}\text { Standard } \\
\text { deviation }\end{array}$ \\
\hline children & 6 & $5-7$ & 111.6 & 12.5 \\
preadolescents & 10 & $8-12$ & 101.5 & 18.9 \\
adolescents & 10 & $13-16$ & 97.0 & 21.1 \\
young adults & 10 & $20-24$ & 67.8 & 21.9
\end{tabular}

Figure 4 shows the results from a series of studies testing responsiveness to different alarm signals using sleeping children aged 6 to 10 years [27]. It was found that the children awoke to only $57 \%$ of the $89 \mathrm{dBA}$ signal presentations of the high pitched smoke alarm (approx $4000 \mathrm{~Hz}-5000 \mathrm{~Hz}$ ). By contrast, arousal rates were $94 \%$ or more with the other $89 \mathrm{dBA}$ signals, which were recordings of their mother's voice (saying their name about once every 6 seconds), female actor's voice alarm and low pitched T-3 alarm. All these more effective signals had dominant tones below 2,500 Hz. The time taken for the child to wake up was also less with these latter three signals, with all awakenings within 60 seconds. In contrast, nearly a third of the children who woke up with the high pitched signal required longer than 60 seconds. 


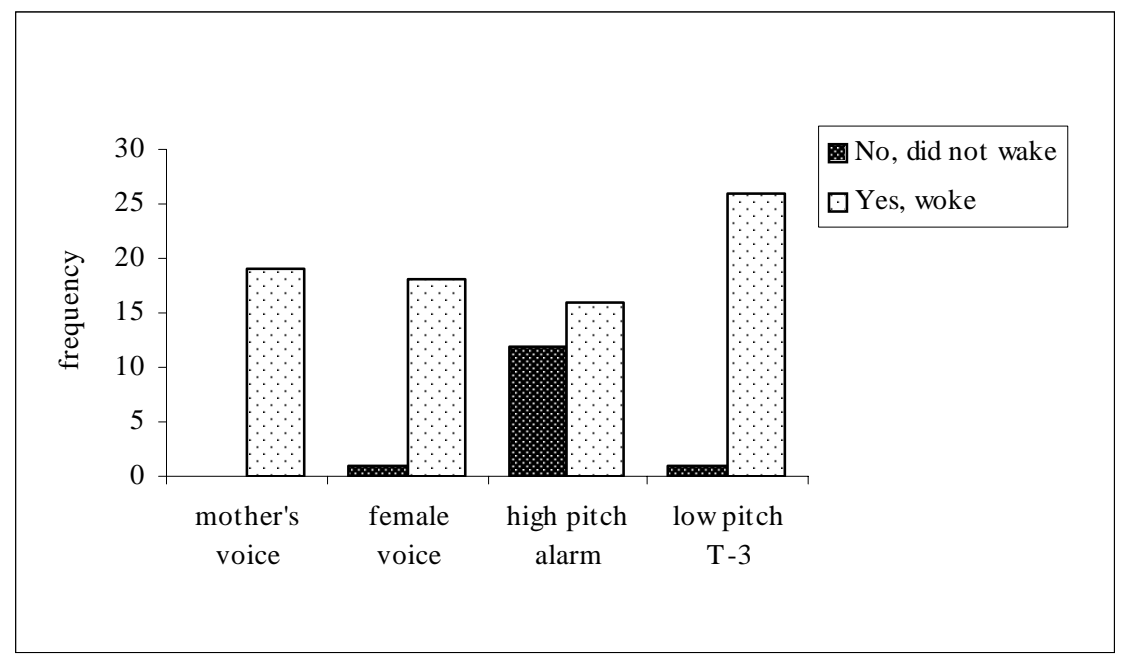

Fig. 4. Number of children who did or did not awaken to different alarm signals [27].

\section{Adults 'Impaired'}

In developed countries sleeping tablets are widely used, with approximately one in five adults using them frequently in the US [28]. In North America the elderly are approximately three times more likely to use hypnotics than younger individuals [29]. It is known that when hypnotics are exerting their maximum effects the chance of waking up to a $78 \mathrm{dBA}$ high pitched alarm is effectively halved [30]. Alcohol is a more widely used soporific substance and statistical analyses of fire fatality data shows it greatly increases the probability of death from fire across all adolescent and adult age groups to the extent that it has emerged as the single most important risk factor for fire fatality [8]. It is hypothesised that this increased mortality rate may result from a range of factors associated with alcohol intoxication, including sleeping through the alarm, not correctly interpreting the alarm, responding inappropriately and/or poor motor functioning. What has been recently established is that responsiveness to alarms during sleep is significantly impaired by alcohol [10]. Using the same group of 12 young adult participants across different types of alarms and different levels of intoxication (see Fig. 5), MANOVA analyses showed significant main effects for both alcohol and different alarms (using the time taken to respond to the alarm in the method of limits procedure as the dependent variable). Thus the high pitched alarm performed significantly worse than the other two signals, and even moderate alcohol intake (0.05 Blood Alcohol Content, BAC) produced significant impairment in the ability to arouse. For the high pitched alarm an average increase in sound volume of $12.5 \mathrm{dBA}$ was required to arouse someone with $0.05 \mathrm{BAC}$ compared to the sober condition. Moreover, regardless of signal, 36\% of those with 0.05 BAC either needed $95 \mathrm{dBA}$ to wake up or did not wake up to 3 minutes of an alarm at this volume. With 0.08 BAC nearly half (47\%) needed $95 \mathrm{dBA}$ or did not awake at all. Further analyses of this data using sophisticated stochastic modeling [31], showed that females were significantly more sensitive to the alarms than males, across all levels of intoxication and signals. 


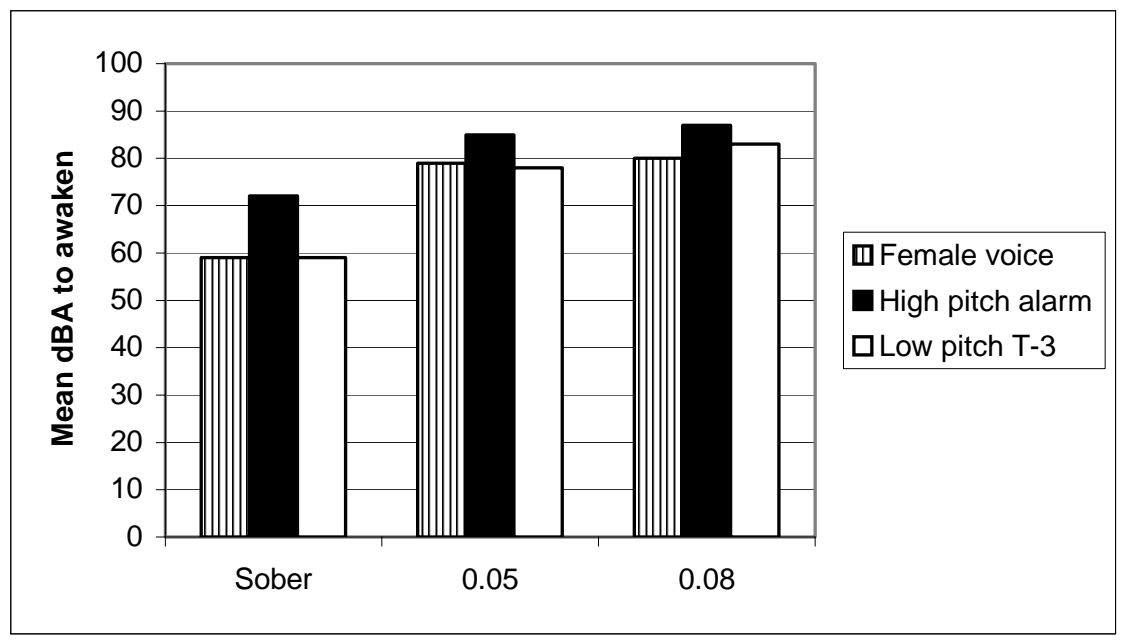

Fig. 5. Comparison of the mean dBA levels of different alarms required to awaken young adults under different blood alcohol content conditions $(n=12)$ [10].

Impairment in the ability to hear high pitched sounds is usual with advancing age, although many people may be unaware of such impairment. A US survey of over 3,700 people aged 48-92 years [32] reported a prevalence of hearing loss ( $>25 \mathrm{~dB})$ of $45.9 \%$. Fig. 6 plots the mean hearing thresholds for 60-69 year old males and females for both a low and high pitched pure tone. From the age of 60 onwards a high pitched sound $(3000 \mathrm{~Hz})$ needs to be at least $30 \mathrm{~dB}$ louder to be heard by a male person when awake than a $500 \mathrm{~Hz}$ sound [32]. Standard deviations are large, especially at the higher pitch levels. The difference in hearing thresholds between when one is awake and asleep changes with age. For the age group under consideration the threshold may be about $40 \mathrm{dBA}$ or more higher when asleep than awake for an $800 \mathrm{~Hz}$ signal [33]. If this difference is generalisable to sounds at other frequency levels then the chances of a male in their 60s waking to a high frequency alarm that is compliant with the regulations become quite slim. Responsiveness during sleep to a $75 \mathrm{dBA} 3100 \mathrm{~Hz}$ alarm has recently been found to be significantly less among the hard of hearing compared to controls [11]. 


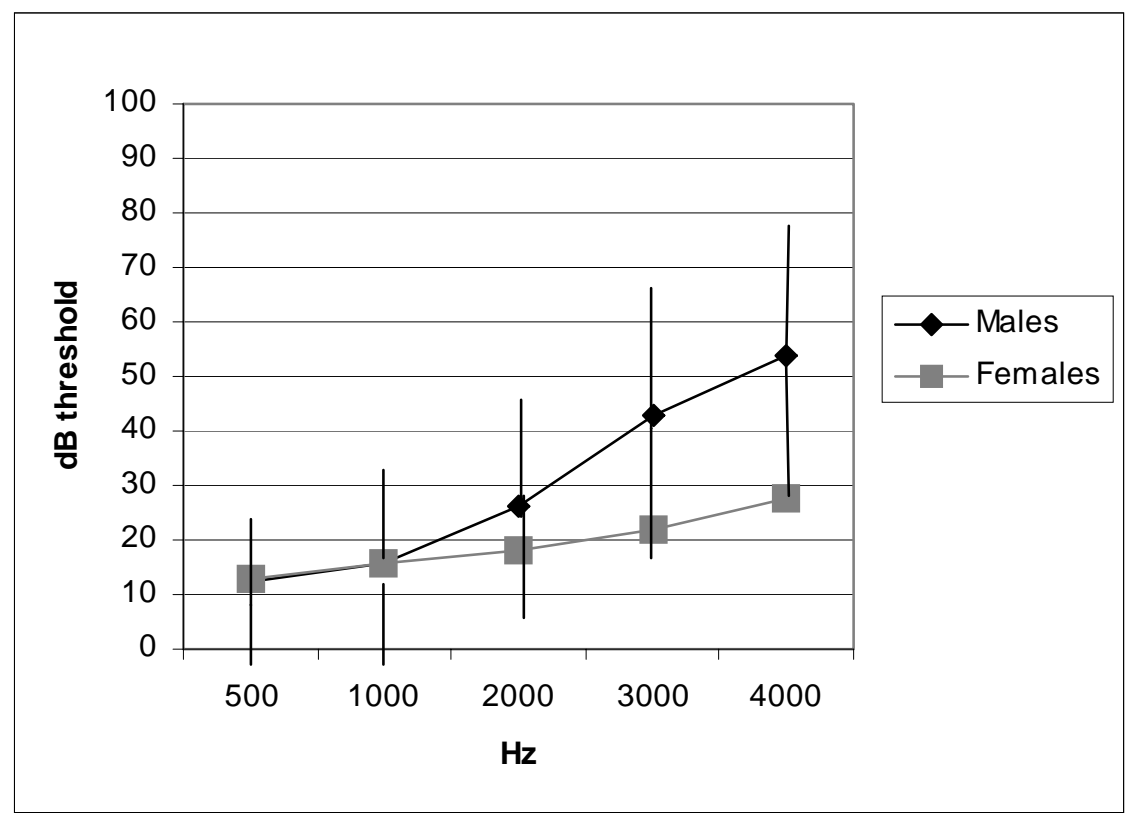

Fig. 6. Mean hearing thresholds (pure tones presented to right ear) by frequency for 60-69 year old males and females (while awake).

Standard deviations shown for males [32].

\section{IMPLICATIONS AND CONCLUSIONS}

In terms of the question within the title of this paper -who is at risk? - it is argued that being asleep is normally not in itself a risk factor. The empirical sleep studies suggest that most unimpaired adults will awaken to either low level fire cues or a smoke alarm that meets the requirements of many countries (i.e., 70 or $75 \mathrm{dBA}$ at the bed head) and have sufficient time to escape. Consistent with this is the data suggesting that there is little difference in the fatality rates of adults aged 17-64 as a function of whether their homes had an operating smoke alarm or not [34]. (Major differences emerge for the elderly and some differences for young people.) Also consistent is the statistic that for $98.5 \%$ of all apartment fires during the sleeping period there are no fire fatalities [1].

However, it is hypothesised that sleep becomes a substantial risk for fire death if additional risk factors are present. Studies of smoke alarms and sleep tells us that significant "staying asleep” risk factors include;

- $\quad$ having high levels of background noise,

- being a heavy sleeper,

- being sleep deprived,

- being a child,

- being under the influence of sleeping tablets,

- being alcohol intoxicated (even moderate, 0.05 BAC), and

- $\quad$ hearing impairment (for high pitch signals this includes many people over 60). 
As these risk factors mean that on any one night a considerable section of the population have an increased chance of sleeping through fire cues or an alarm signal, the issue of what type of alarm signal is optimum must be addressed. Fortunately, the studies that have compared the waking effectiveness of different alarms draw the same conclusions. The evidence from studies using young children, sober adults and alcohol intoxicated adults suggest that such individuals are more likely to awaken to low frequency signals at a lower volume compared to high frequency signals. Both a low pitch T-3 beeping signal and the female voice alarm elicited a behavioural response in sober adults at around $13 \mathrm{dBA}$ less volume than a high pitched alarm [10]. Similarly, the likelihood of a 6 to 10 year old waking to a low pitched T-3 or voice alarm is almost twice as great as awakening to a high pitch alarm at the same loud volume [27]. It is possible that the critical optimal frequencies are those within the same pitch range as the human voice ( $2500 \mathrm{~Hz}$ or less), although one study on the responsiveness of neonates during sleep [35] suggests lower frequencies $(120-250 \mathrm{~Hz})$ are optimal. People representing hard of hearing individuals advocate a tone between 100 and $700 \mathrm{~Hz}$ [36].

There are several important research questions that still need to be addressed:

- In order to be certain that the frequency of the signal is critical to waking effectiveness, comparison of the efficacy of the same signal (e.g., T-3) at a range of high and low pitches is needed. Such studies will help to more narrowly define the most effective frequency band for beeping sounds.

- A study using a larger sample needs to compare responsiveness to a voice alarm and a beeping signal in the frequency range found to be the most effective.

- If a voice alarm is better than beeping, is a female voice better than a male voice? A female voice was chosen in the above studies because of research showing that a female voice was perceived as more urgent than a male voice by individuals when awake [37]. However, given that the low pitched T-3 was found to be as effective as the female voice [10] urgency may not be a critical factor in differential arousal from sleep.

- Perhaps the best signal is one that incorporates a signal shift between a voice and beeping. However, the one study that has considered a signal shift found that a 5 sec shift produced no advantage [38].

- In most of the sleep studies the participants were expecting a smoke alarm or fire cue to be presented, although sometimes they only knew it would occur on one of several possible nights. Thus, they were 'primed' to expect to be awoken and it is known from several early sleep studies that such priming can increase responsiveness during sleep. Priming to respond to particular signals during sleep can increase awakenings from $25 \%$ to $90 \%$ [39]. Thus the data may overestimate of the real rate of responding to unanticipated signals and further research on this variable is required.

- Data collection from attended fires should always seek a comprehensive recording of multiple risk factors (if they are evident). This would help reveal the possible contribution of additional risk factors in sleeping victims.

The consistency of the findings in the empirical sleep studies using children, sober adults and intoxicated adults is encouraging. Perhaps this consistency will also extend to similar differences in waking with different signals in other vulnerable populations, such as the sleep deprived and those on sleeping tablets. If so, children may prove to be a convenient 
and useful "model" population to test some of the above research issues. The applicability of the findings across different age groups also needs study, especially given the high rates of hearing loss with age within the population.

If further research supports the current conclusions about the increased efficacy of lower frequencies then it will be important for the published standards for emergency signals (such as the ISO 8201) to include relevant recommendations about signal frequency that can then be adopted by different regulatory bodies internationally. At this stage the benefits of suggesting a frequency range of below $2500 \mathrm{~Hz}$ include:

- demonstrated increased waking effectiveness in selected populations (children, sober adults, and alcohol intoxicated adults).

- demonstrated superior ability of frequencies below $500 \mathrm{~Hz}$ to penetrate through walls and doors [13].

- hypothesised increased waking effectiveness in those with high frequency hearing impairment, such as is associated with aging.

- hypothesised increased waking effectiveness in other currently vulnerable populations such as those who are sleep deprived or on sleeping tablets.

Further investigation is also required to determine whether the most efficacious low frequency signals can be easily and cheaply emitted by an alarm unit of the current size of a smoke detector.

\section{REFERENCES}

[1] Thomas, I.R., and Verghese, D., "CESARE-RISK: A Summary Report," Victoria University and Fire Code Reform Centre Ltd, (Appendix F), June, 2001.

[2] Ahrens, M., "US Experience with Smoke Alarms and Other Fire Detection/Alarms Equipment," National Fire Protection Association, Quincy, MA, November, 2004.

[3] Fahy, R., and Molis, J., "Fatalities in Home Fires Where Smoke Alarms Operated," In Proceedings of the Third International Symposium on Human Behaviour in Fire, Interscience Communications, 2004, pp. 57-67.

[4] Thomas, I., and Brennan, P., "Injuries and Fatalities in Apartment Building Fires," Fire Safety Science - Proceedings of the Seventh International Symposium, International Association for Fire Safety Science, 2002, pp. 10851096.

[5] Sekizawa, A., "Statistical Analyses on Fatalities Characteristics of Residential Fires," Fire Safety Science - Proceedings of the Third International Symposium, International Association for Fire Safety Science, 1991, pp. 475-484.

[6] Bruck, D., "The Who, What, Where and Why of Waking to Alarms: A Review," Fire Safety Journal, 36, pp. 623-639, (2001).

[7] Brennan P., "Victims and Survivors in Fatal Residential Building Fires," Human Behaviour in Fire- Proceedings of the First International Symposium, Fire SERT Centre, University of Ulster, 1998, pp. 157-166. 
[8] Runyan, C.W., Bangdiwala, S.I., Linzer, M.A., Sacks, J.J., and Butts, J., "Risk Factors for Fatal Residential Fires," The New England Journal of Medicine, 327, (12), pp. 859-863, (1992).

[9] Nober, E.H., Peirce, H., and Well, A.D., "Acoustic Spectral Characteristics of Household Smoke Detector Alarms,” Fire Journal, pp. 94-98, (May, 1981).

[10] Ball, M., and Bruck, D., "The Effect of Alcohol Upon Response to Different Fire Alarm Signals," Proceedings of the Third Human Behaviour in Fire Conference, Interscience Communications, 2004, pp. 291-302.

[11] Ashley, E., Du Bois, J., Klassen, M., and Roby, R., "Waking Effectiveness of Audible, Visual and Vibratory Emergency Alarms Across All Hearing Levels," Fire Safety Science - Proceedings of the Eighth International Symposium, International Association for Fire Safety Science, 2005 (poster presentation this volume).

[12] Kahn, M.J., "Human Awakening and Subsequent Identification of Fire-related Cues,” Fire Technology, 20 (1), pp. 20-26, (1984).

[13] Robinson, D.A.," Sound Transmission Loss from Corridors to Rooms: Implications for Locating Fire Alarm Sounders,” Fire Technology, 22, (2), pp. 122-135, (1986).

[14] ISO 8201, “Acoustics- Audible emergency evacuation signal,” International Organisation for Standardisation, Geneva, Switzerland, 1987.

[15] Proulx, G., and Laroche, C., "Recollection, Identification and Perceived Urgency of the Temporal-three Evacuation Signal,” Journal of Fire Protection Engineering, 13, pp. 67-82, (2003).

[16] Bonnet, M., "Performance During Sleep," in Biological Rhythms, Sleep and Performance, W.B. Webb (ed.), J. Wiley \& Sons, 1982, pp. 205-237.

[17] Bruck, D., and Horasan, M., "Non-arousal and Non-action of Normal Sleepers in Response to a Smoke Detector Alarm,” Fire Safety Journal, 25, pp. 125-139, (1995).

[18] Snyder, F., and Scot, J., “The Psychophysiology of Sleep,” In: Handbook of Psychophysiology, N.S. Greenfield and RA Sternback (eds.), New York, Holt, Rinehart and Winston, 1972.

[19] Williams, H.L., Hammack, J.T., Daly, R.L., Dement, W.C., and Lubin, A.L., "Responses to Auditory Stimulation, Sleep Loss and the EEG Stages of Sleep," Electroencephalography and Clinical Neurophysiology, 16, pp. 269-279, (1964).

[20] Broman, J.E., "Insufficient Sleep in the General Population," Neurophysiologie Clinique, 26, (1), pp. 30-39, (1996).

[21] Rajaratnam, S.M., and Arendt, J., "Health in a 24-h Society," Lancet, 358 (9286), pp. 999-1005, (Sept 22, 2001).

[22] Nober, E.H., Peirce, H., and Well, A., "Waking Effectiveness of Household Smoke and Fire Detection Devices,” Fire Journal, pp. 86-91, (July 1981). 
[23] Bruck, D., "Non-awakening in Children in Response to a Smoke Detector Alarm,” Fire Safety Journal, 32, pp. 369-376, (1999).

[24] Bruck, D., and Brennan, P., "Recognition of Fire Cues During Sleep,” In Human Behaviour in Fire- Proceedings of the Second International Symposium, Interscience Communications, 2001, pp. 241-251.

[25] Astrom, C., and Trjaborg, W., "Relationship of Age to Power Spectrum Analysis of EEG During Sleep,” Journal of Clinical Neurophysiology, 9, (3), pp. 424-430, (1992).

[26] Busby, K.A., Mercier, L., Pivik, R.T., "Ontogenic Variations in Auditory Arousal Threshold During Sleep,” Psychophysiology, 31, pp. 182-188, (1994).

[27] Bruck, D., and Ball, M., "The Effectiveness of Different Alarms in Waking Sleeping Children," In Proceedings of the Third International Symposium on Human Behaviour in Fire, Interscience Communications, 2004, pp. 279-290.

[28] Hauri, P., and Linde, S., No More Sleepless Nights, New York: J. Wiley and Sons, 1990.

[29] Hall, N., "Taking Policy Action to Reduce Benzodiazepine Use and Promote Self-care Among Seniors,” J Applied Gerontology, 17, (3), pp. 318-352, (1998).

[30] Johnson, L.C., Spinweber, C.L., Webb, S.C., and Muzet, A.G., "Dose Level Effects of Triazolam on Sleep and Response to a |Smoke Detector Alarm," Psychopharmacology, 91, pp. 397-402, (1987).

[31] Hasofer, M., Thomas, I.R., Bruck, D., and Ball, M., "Statistical Modelling of the Effect of Alcohol and Sound Intensity on Response to Fire Alarms," Fire Safety Science - Proceedings of the Eighth International Symposium, International Association for Fire Safety Science, 2005 (this volume).

[32] Cruickshanks, K.J., Wiley, T. L., Tweed, T.S., Klein, B.E.K., Klein, R., MaresPerlman, J.A., and Nondahl D.M., "Prevalence of Hearing Loss in Older Adults in Beaver Dam, Wisconsin: The Epidemiology of Hearing Loss Study,” Am J Epidemiol, 148, (9), pp. 878-886, (1998).

[33] Zepelin, H., McDonald, C.C., and Zammit, G.K., " Effects of Age on Auditory Awakening,” J. Gerontology, 39, (3), pp. 294-300, (1984).

[34] Norris, C., "A Tour d'horizon of Government Fire Policy and the Role of Fire Research," In Proceedings of the Third International Symposium on Human Behaviour in Fire, Interscience Communications, 2004, pp 1-10.

[35] Weir, C., "Auditory Frequency Sensitivity in the Neonate: A Signal Detection Analysis,” Journal of Experimental Child Psychology, 21, pp. 219-225, (1976).

[36] Mulvany, D., Submission to NFPA Technical Committee re NFPA 72, 2002, $11 / 5 / 2004$, personal communication.

[37] Hellier, E., Edworthy, J., Weedon, B., Walters, K., and Adams, A. "The Perceived Urgency of Speech Warnings' Semantics Versus Acoustics,” Human Factors, 44, pp. 1 - 16, (2002). 
[38] Ball, M., and Bruck, D., "The Salience of Fire Alarm Signals for Sleeping Individuals: A Novel Approach to Signal Design," In Proceedings of the Third International Symposium on Human Behaviour in Fire, Interscience Communications, 2004, pp. 303-314.

[39] Wilson, W.P., and Zung, W.K., "Attention, Discrimination, and Arousal During Sleep,” Archives of General Psychiatry, 15, pp. 523-528, (1966). 
